\title{
Information for managers in hospitals: representing maternity unit statistics graphically
}

\author{
A SZCZEPURA, M MUGFORD, J A STILWELL
}

\begin{abstract}
Staff who organise and run maternity units contribute many statistics to their health authority but do not find it easy to obtain information about their unit from these statistics. Data that are collected routinely, however, can be used to provide each unit with a graphical profile of its activity and resources. The method described here was derived from the personality profiles used by psychologists and allows staff in one unit to assess the outcome, activity, and use of resources in their unit in relation to similar units, to explain some of the differences when these occur, or to highlight potential problems. Examples are taken from a study of maternity units in the West Midlands.

It is concluded that the technique can indicate potential problems and usefully be adopted by those who monitor maternity care in districts or hospitals.
\end{abstract}

\footnotetext{
Institute for Management Research and Development, University of Warwick, Coventry CV4 7AL

A SZCZEPURA, MA, DPHIL, research fellow

J A STILWELL, MA, head of health services research unit

National Perinatal Epidemiology Unit, Radcliffe Infirmary, Oxford M MUGFORD, BA, unit economist

Correspondence to: Institute for Management Research and Development.
}

\section{Introduction}

There is no shortage of statistics about district and national maternity services because these are collected routinely. ${ }^{1}$ Recent publications have discussed what statistical information managers in the health service need, ${ }^{2-4}$ and the data required to monitor maternity care have also been considered ${ }^{5}{ }^{6}$ and statistical tabulations suggested. ${ }^{7}$ But for those who use and run these services in hospitals finding data about their own activities and resources and comparing these with data from other units is difficult. In business it is accepted that decision makers need information about the characteristics of their own organisation set against a background of the overall pattern for similar organisations. The continuing success of the Profit Impact of Market Strategies set up by the Harvard Business School shows that managers find such information useful. ${ }^{8}$

Building on various approaches to this problem, we have developed a graphical method to show statistical data about the use of resources and outcomes. The amount of information is maximised, and yet it is clearly and simply presented. We have named these diagrams management awareness profiles or MAPs. We used this method to present data on maternity hospitals in the West Midlands health region, and in this paper we analyse its value and further applications.

\section{Background}

In 1984 we received a grant from the Department of Health and Social Security to examine the relation between the resources that were available at maternity hospitals and the outcome of births at these hospitals. During this study we collected data in the West Midlands region about the demands placed on maternity units in terms of the distribution of birth weights and the numbers of births; the resources, particularly staff, at each unit; the use made of the facilities of other units owing to transfers for neonatal care; and the outcomes of the births that occurred in each unit (table I). Data on resources were collected in a detailed survey of maternity units. We derived statistics about births, transfers, and outcomes from Hospital Activity 
Analysis tapes that were supplied by the regional health authority. The details of the methods and main conclusions of this study will be reported elsewhere.

We discovered that the clinical managers who responded to our survey in hospitals often wished for more feedback from the routine statistical

\begin{tabular}{l} 
TABLE I-Items on which data were collected \\
in the study of West Midland maternity units \\
\hline Births at each hospital \\
Dates of birth and discharge of baby \\
Birth weight \\
Whether malformed \\
Whether baby died or was discharged alive \\
Age at death if baby died \\
Resources at each hospital \\
Staff: \\
Midwives \\
Nurses \\
Other (non-clinical) staff \\
Medical staff \\
Equipment, buildings, and services: \\
Distances of maternity unit from key services \\
Call out times \\
Key items of equipment in labour ward and \\
special care unit
\end{tabular}

opinion as useful for monitoring maternity care and which were available from our study. ${ }^{6} 6$ We emphasised items that we found had an important bearing on outcome and thus included data on transfers. This both shows the hospital's use of facilities for special and intensive care at other hospitals and extends the normal outcome measures, which usually include only deaths in the hospital of birth. Table II lists and defines the items that we selected. These include measures of the type of births a unit cares for and of outcome and resources. It is always difficult to select appropriate and specific data to present while keeping the number of items of information to a minimum. It is, for example, difficult to interpret crude perinatal mortality and better to consider separately the experience of births in different risk categories as they represent different proportions of births in different units and place different demands on those units. ${ }^{10}$ We selected $1500 \mathrm{~g}$ birth weight as the division in preference to a $2500 \mathrm{~g}$ upper limit for low birth weight, which is more generally used, because both national statistics ${ }^{1}$ and the results of our research suggest that this group of infants represents a more consistently high risk category in different ethnic and social groups than does the wider range of low weight births.

\section{Management awareness profiles}

"Profile" has been used to describe many different ways of presenting statistical data. In general, it refers to a descriptive presentation of numerical information about units or individuals that shows, for each of a range of

TABLE II-Definition and description of items included in management awareness profile and sources of data

\begin{tabular}{|c|c|c|}
\hline Item & Description & Source of data \\
\hline $\begin{array}{l}\text { In house perinatal mortality rate: } \\
\text { Babies }>1500 \mathrm{~g}\end{array}$ & $\begin{array}{l}\text { Stillbirths and deaths in the first week occurring at that } \\
\text { hospital per } 1000 \text { live and stillbirths }>1500 \mathrm{~g} \text {. } \\
\text { Excludes babies with unknown birth weight }\end{array}$ & $\begin{array}{l}\text { For all but two hospitals, our analysis of West Midlands } \\
\text { Region Hospital Activity Analysis computer tape. For } \\
\text { one hospital complete processing of non-computerised } \\
\text { records. For one hospital data from hospital reports } \\
\text { and hospital computer system }\end{array}$ \\
\hline Babies $\leqslant 1500 \mathrm{~g}$ & $\begin{array}{l}\text { Stillbirths and deaths in the first week occurring at that } \\
\text { hospital per } 1000 \text { live and stillbirths } \leqslant 1500 \mathrm{~g} \text {. } \\
\text { Excludes babies with unknown birth weight }\end{array}$ & As above \\
\hline $\begin{array}{l}\text { Births } \leqslant 1500 \mathrm{~g} \\
\% \text { Babies } \leqslant 1500 \mathrm{~g} \text { transferred }\end{array}$ & $\begin{array}{l}\% \text { Of all births in the hospital weighing } \leqslant 1500 \mathrm{~g} \\
\% \text { Of total number of babies born at the hospital } \\
\text { weighing } \leqslant 1500 \mathrm{~g} \text { who are subsequently transferred } \\
\text { to another hospital for special care or surgery }\end{array}$ & $\begin{array}{l}\text { As above } \\
\text { Analysis of West Midlands Region Hospital Activity } \\
\text { Analysis computer tape using program devised by us }\end{array}$ \\
\hline Neonatal mortality rate after transfer & $\begin{array}{l}\text { Deaths up to } 28 \text { days of age of babies born at the unit } \\
\text { and subsequently transferred to another hospital } \\
\text { within the region per } 1000 \text { total births at the unit } \\
\text { (all weights) }\end{array}$ & As above \\
\hline Size & Annual number of births at the unit & $\begin{array}{l}\text { For all but two hospitals, our analysis of West Midlands } \\
\text { Region Hospital Activity Analysis computer tape. For } \\
\text { one hospital complete processing of non-computerised } \\
\text { records. For one hospital data from hospital reports and } \\
\text { hospital computer system }\end{array}$ \\
\hline Midwives per 1000 births & $\begin{array}{l}\text { Numbers of whole time equivalent, qualified midwives. } \\
\text { Average of figures for } 31 \text { March and } 30 \text { September } \\
\text { per } 1000 \text { total births }\end{array}$ & $\begin{array}{l}\text { Data collected from unit midwifery managers by our } \\
\text { survey }\end{array}$ \\
\hline Other nurses per 1000 births & $\begin{array}{l}\text { Number of whole time equivalent state registered } \\
\text { nurses, state enrolled nurses, nursery nurses, and } \\
\text { auxiliaries employed at the unit. Average of figures } \\
\text { for } 31 \text { March and } 30 \text { September per } 1000 \text { total } \\
\text { births. Excludes students }\end{array}$ & As above \\
\hline Obstetricians per 10000 births & $\begin{array}{l}\text { Numbers of obstetric medical staff, all grades, working } \\
\text { at the unit. Average of figures for } 31 \text { March and } \\
30 \text { September per } 10000 \text { total births }\end{array}$ & $\begin{array}{l}\text { As above, supplemented by information from medical and } \\
\text { administrative personnel at unit and district level }\end{array}$ \\
\hline Paediatricians per 10000 births & $\begin{array}{l}\text { Numbers of paediatric medical staff, all grades, } \\
\text { working at the unit. Average of figures for } 31 \text { March } \\
\text { and } 30 \text { September per } 10000 \text { total births }\end{array}$ & As above \\
\hline
\end{tabular}

systems. The data that are collected routinely about maternity care are not normally analysed for individual hospitals. Though much thought has been given to the collection of data for managing the health service, relatively little thought and research have gone into how the data might be returned to managers in a useful and flexible form. A department of health steering group on health services information recommended a minimum set of data for monitoring maternity services; but it was not within their brief to suggest how this might be used. ${ }^{2}$ Little emphasis was given to linking sets of data about clinical activity and use of resources, for instance. Indeed, it was recommended elsewhere in the reports that clinical data should be aggregated by calendar year, though information about beds and staff should be aggregated by financial year. ${ }^{2}$ But if district health authorities follow the recommendation of the National Health Service data model there should be sufficient flexibility to allow tabulation by more than one time period. ${ }^{9}$

To illustrate the potential use of MAPs for consultant obstetric units we used items that were selected by a consensus of clinical and administrative indicators, how the value for a particular unit is related to the values for all the other units. The methods used include bar charts, simple percentile bars, and more complex approaches. In Britain statistical data that are collected routinely have been presented in the past to the health service by using simple profiles. ${ }^{11} 12$ These profiles have been used mainly for district data and hospital based data in mental illness and mental handicap.

A slightly different approach was used by Selbmann and colleagues in the Bavarian perinatal survey. ${ }^{13}$ In this study more complex profiles were introduced that were hospital based. Selbmann et al were, however, principally concerned with clinical practice and not with resources, such as staffing.

To manage a maternity service, whether it is a single unit or a regional service, information is needed about both resources and outcomes. Figure 1 illustrates how a MAP constructs a picture of a unit from the items of data listed in table II. The key items that are included were divided into two groups. The upper section shows demands and outcomes, and the lower 
section concentrates on resources. Each horizontal line in fig 1 shows the distribution in our sample of 22 consultant maternity units in terms of the upper and lower values, the 10th and 90th percentiles, and the median. To achieve an uncluttered presentation we omitted the actual figures for the upper and lower values. Because the MAP uses a linear scale these may be inferred from the other values. The medians for each item are positioned so that they fall on the same vertical line. The points at which the 10th and 90th percentiles fall are joined by lines, similar to the contours found on maps joining all places that are the same height above sea level. When areas enclosed by these contours are shaded in, the MAP produced shows a clear background picture of existing practice or provision for consultant obstetric units in the West Midlands. For one hospital the value for each item can be plotted and a line drawn to join all these points. This then constitutes that unit's maternity MAP. Where an observation for a unit falls outside the shaded area this indicates that the hospital is one of the $10 \%$ of units at each

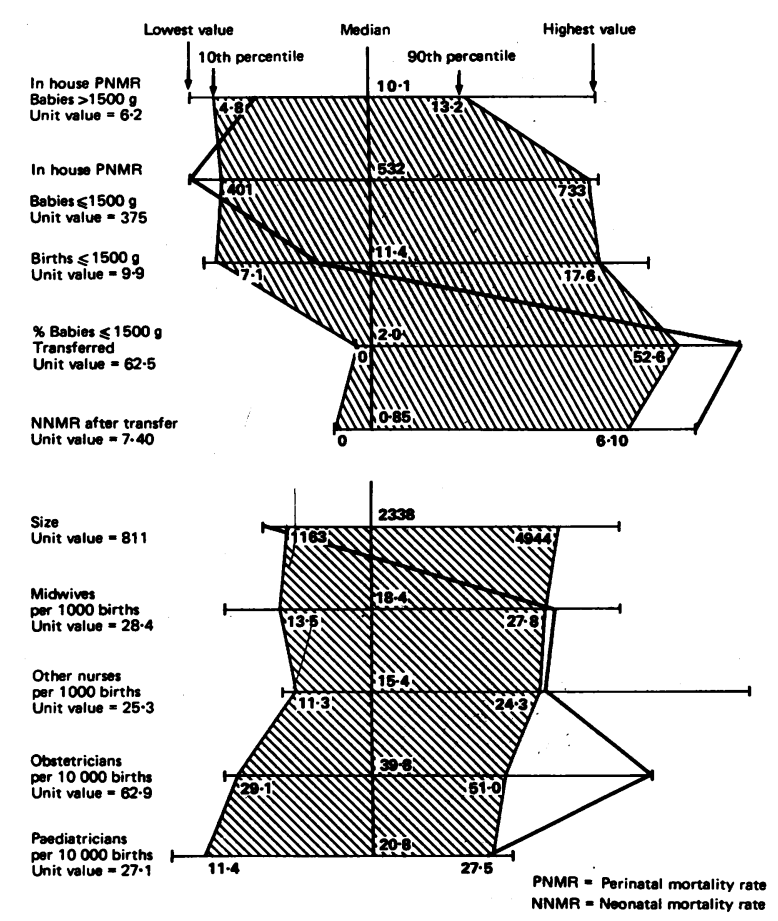

FIG 1-Management awareness profile (MAP) for hospital A (1978). See table II. end of the range. The shaded area, representing the values for the remaining $80 \%$ of hospitals, should not, however, be interpreted as a confidence interval in the statistical sense. The items in the MAP are not independent, and some, being ratios rather than proportions, are not amenable to simple parametric tests. We have excluded general practitioner units from this analysis, so that like is compared with like.

While collecting data for our study we found, as others have, ${ }^{14}$ that some routinely collected data were never used and were seriously inaccurate as a result. Therefore the first response to MAPs that seem surprising should be to check the data, and a table of the raw data from which the MAP was drawn should accompany it.

\section{Using MAPs}

MAPs can be used to look at a single hospital in its regional context, to compare hospitals of similar type, and to examine trends over time. Figure 1 shows a single hospital in the context of its region. The upper section of the MAP shows that the hospital has low perinatal mortality, especially for babies whose birth weight was $\leqslant 1500 \mathrm{~g}$. It, however, transfers $62 \%$ of these low birthweight babies, compared with a regional median value of $2 \%$. When the outcome is considered for all babies whom the unit transfers the neonatal mortality rate for these babies is the highest in the region and in fact adds a value of $7 \cdot 4$ per 1000 births to the mortality rate calculated using deaths that occur in the unit (in house deaths). The lower half of the MAP shows that this unit was not understaffed and that its problems may be associated with its small size.

The value of a MAP is increased by looking at a series of MAPs for a particular hospital over a period of time. Such a time series is shown for hospital B in fig 2. The bottom sections of the MAPs show that hospital size, obstetric staffing levels, and non-midwifery nursing levels are within the normal range. The hospital, however, has been consistently poorly staffed in midwives in relation to other units in the region. Over the period 1978-82 the paediatric staffing level improved, until by 1982 it was above the 90th percentile value for the region. The regional median figure for nursing staff increased only slightly over this period and that for medical staff remained virtually unchanged. So for this unit, which is relatively understaffed in midwives, what features are apparent in the upper section of the profile? The in house perinatal mortality values for small babies (birth weight $\leqslant 1500 \mathrm{~g}$ ) and also for the larger babies (birth weight $>1500 \mathrm{~g}$ ) are low. Similarly, the percentage of $\leqslant 1500 \mathrm{~g}$ birthweight births is relatively low. The unit, however, has been consistently unable to cope with the small proportion of low birthweight babies that are born there and relative to the trend shown by other units in the region it has progressively transferred more and more of these infants. Also, over this period the survival rate of all babies who were transferred was poor, and in relation to the other units in the region it had become worse and worse. This then was a hospital with visible problems, and in fact the unit has been closed and moved to a new site.

In fig 3 MAPs are used to look at two hospitals, $\mathrm{Cl}$ and $\mathrm{C} 2$, for the years

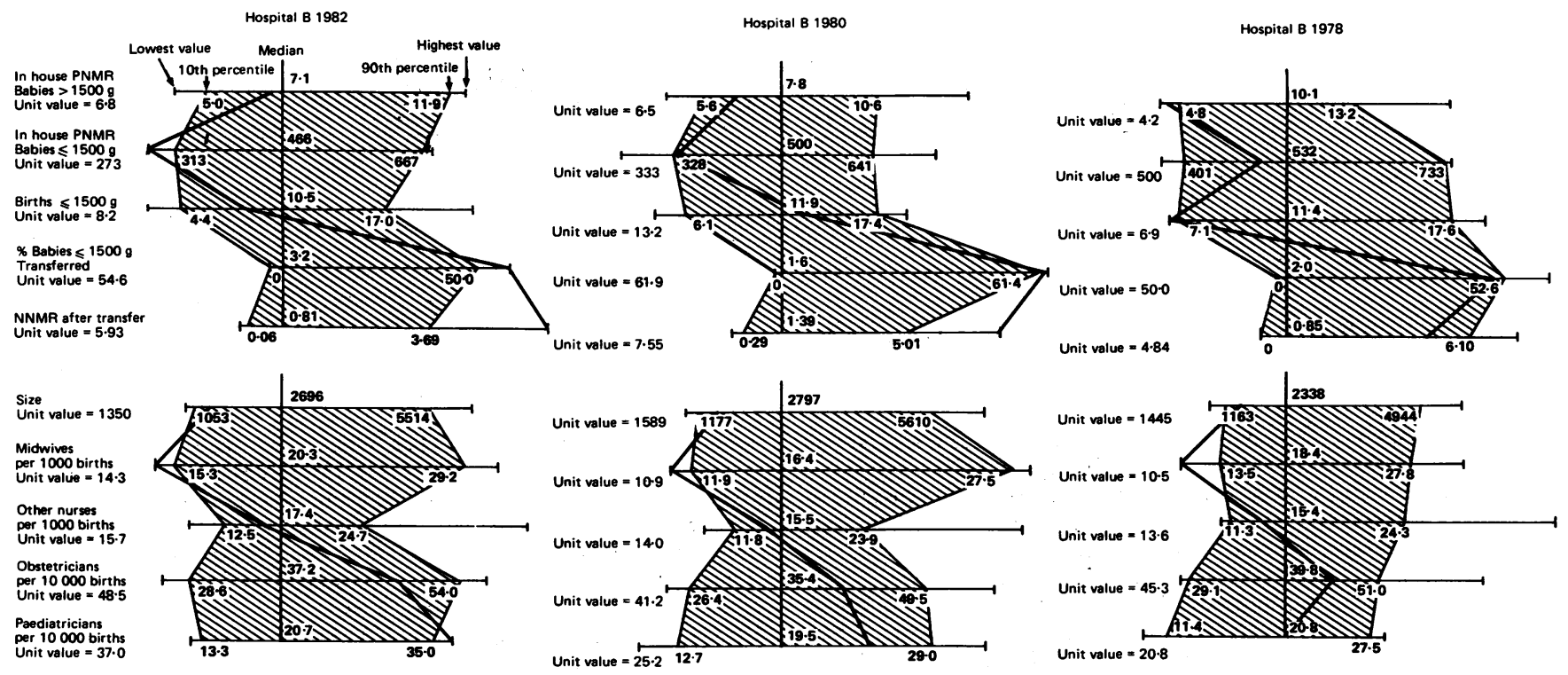

PNMR $=$ Perinatal mortality rate
NNMR $=$ Nonotal mortality rate

FIG 2-Management awareness profile (MAP) for hospital B in 1982, 1980, and 1978. See table II. 
Hospital Cl 1982
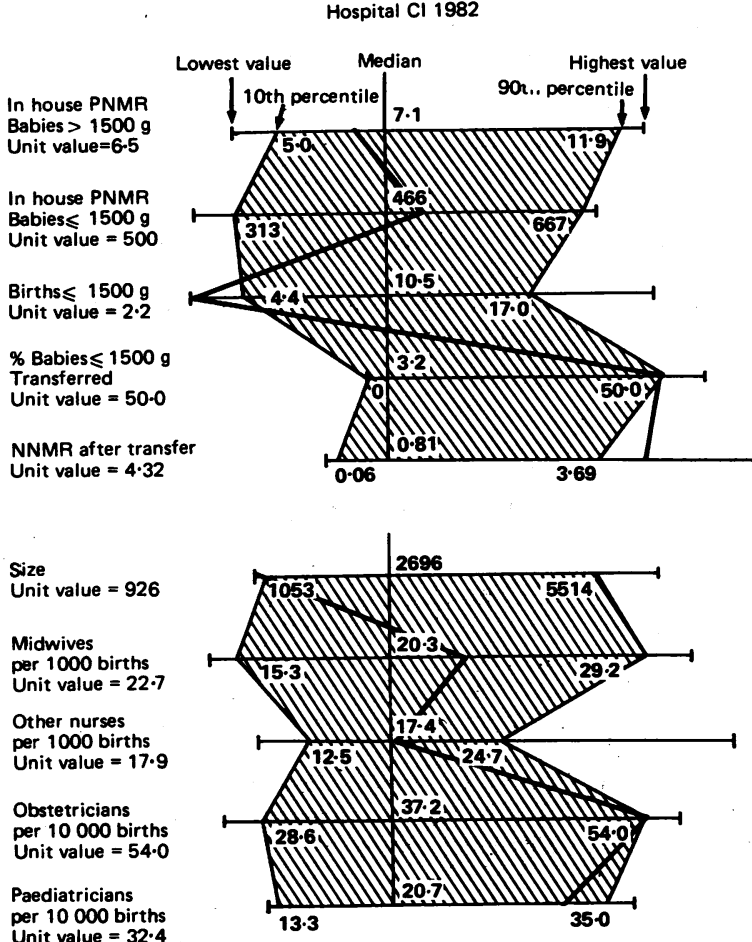

per 10000 births
Unit value $=6.64$

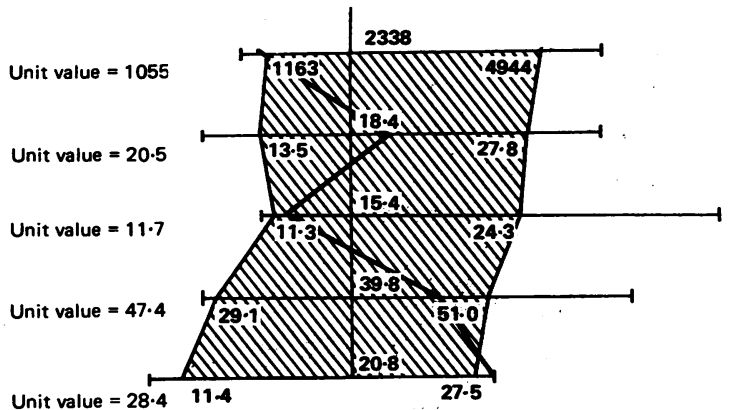

Unit value $=28.4 \quad 11.4$

Hospital Cl 1978

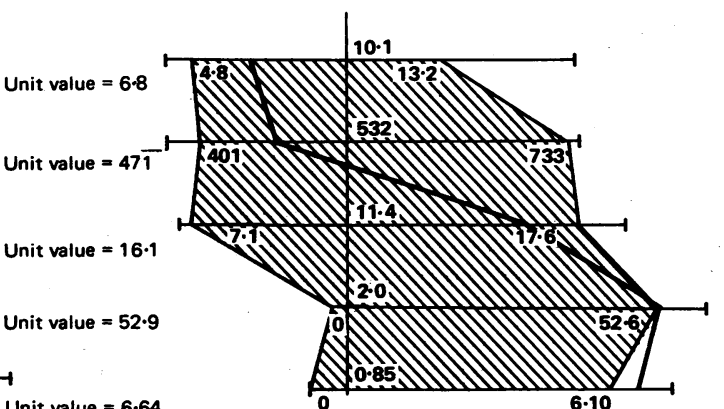

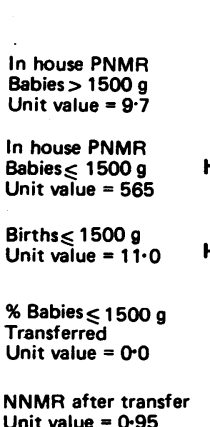

Hospital C2 1982

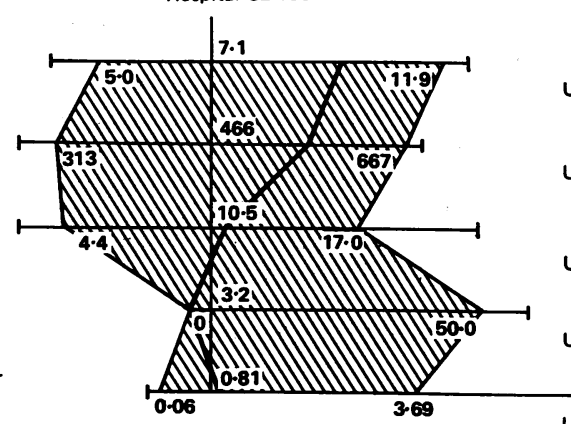

Unit value $=0.95$

Size
Unit value $=2097$

Midwives

per 1000 births
Unit value $=27.1$

Other nurses

Other nurses
per 1000 births
Unit value $=40.6$

Obstetricians

per 10000 births
Unit value $=28 \cdot 6$

Paediatricians

per 10000 births
$U$ Unit value $=19 \cdot 1$

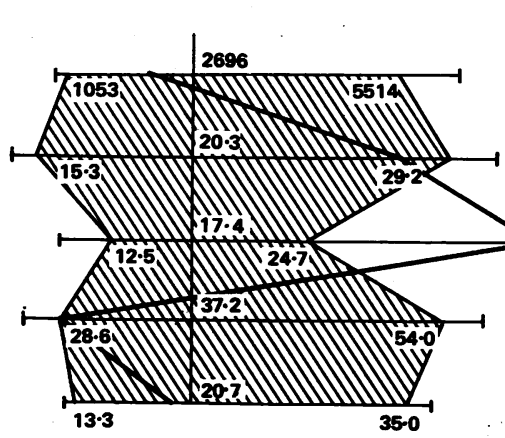

Unit value $=0.51$

Unit value $=1942$

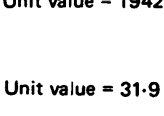

Unit value $=31.9$

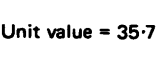

Unit value $=30.9$

Unit value $=20 \cdot 6$
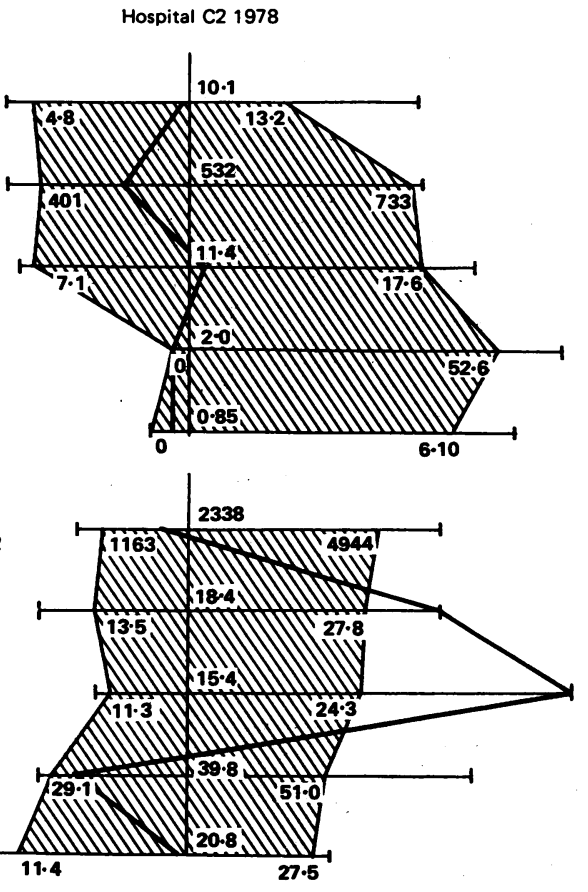

PNMR = Perinatal mortality rate

NNMR $=$ Neonatal mortality rate

FIG 3-Management awareness profile (MAP) for hospital C1 and hospital C2 in 1982 and 1978. See table II.

1978 and 1982. These two hospitals serve a single district. The bottom part of the MAPs for both hospitals shows that $\mathrm{Cl}$ is one of the smallest units in the region and is reasonably well staffed in relation to other units, especially with paediatricians. In $\mathrm{C} 2$ staffing levels are normal for the region except for levels of midwifery and nursing staff, which are high, although the unit's staffing level in midwives has decreased to within the interdecile range. The top sections of the MAPs for both hospitals show that $\mathrm{C} 2$ falls within the normal range, it transfers few small babies, and death rates after transfer are low. Cl transfers a relatively large proportion of its babies of $\leqslant 1500 \mathrm{~g}$ birth weight, as expected, since it is presumably served by the larger unit for intensive care. The survival rate, however, of all babies transferred is poor in relation to that for other units in the region, although the absolute value has improved. Notably, this smaller unit, $\mathrm{Cl}$, has had a decrease in the proportion of births in the $\leqslant 1500 \mathrm{~g}$ category over the period. Presumably, as its working relation with hospital $\mathrm{C} 2$ has improved more high risk births have been moved to $\mathrm{C} 2$ before delivery, although there is no sign of a corresponding increase in births of $1500 \mathrm{~g}$ birth weight or less for this unit.

Finally, fig 4 shows a set of MAPs for hospital D, a large unit with normal medical staffing and non-midwifery nursing levels but with increasingly relatively high staff levels of midwives. The top sections of the MAPs show low in house perinatal mortality values, and rates of death after transfer are also relatively low. The unit, however, has had to cope with a progressively higher proportion of $\leqslant 1500 \mathrm{~g}$ birthweight births, consistently above the 90 th percentile for the region. This, therefore, seems to be a unit that is 
coping relatively well with its in house births. In fact it also takes many low birthweight babies for care, although this is not shown on these MAPs.

The MAPs shown do not include data on resources other than staffing, but they can be adapted to include these.

\section{Discussion}

Our initial intention in drawing unit MAPs was to give the doctors and midwives who participated in our survey some feedback on the data that they had provided for us. Thus we have developed a way of looking at multivariate data that may be understood intuitively by non-statisticians and in a way that covariance matrices profiles did not completely tackle the problem-which is an inherent characteristic of maternity units in Britain-that units may draw on resources in other hospitals by transferring their babies for special or intensive care. We think that the numbers transferred and the outcomes for these babies should be included on the profile for the hospital of birth.

In our approach no judgments are made about the nature of the relations between resources, clinical activity, and outcome, except possibly in the exclusion of some items from the MAP. Thus we do not regard the MAP as a simple performance indicator. If MAPs are used for a long time or achieve widespread use certain patterns may emerge that identify better managed units in the same way that psychological profiles can be drawn for typical personality types.

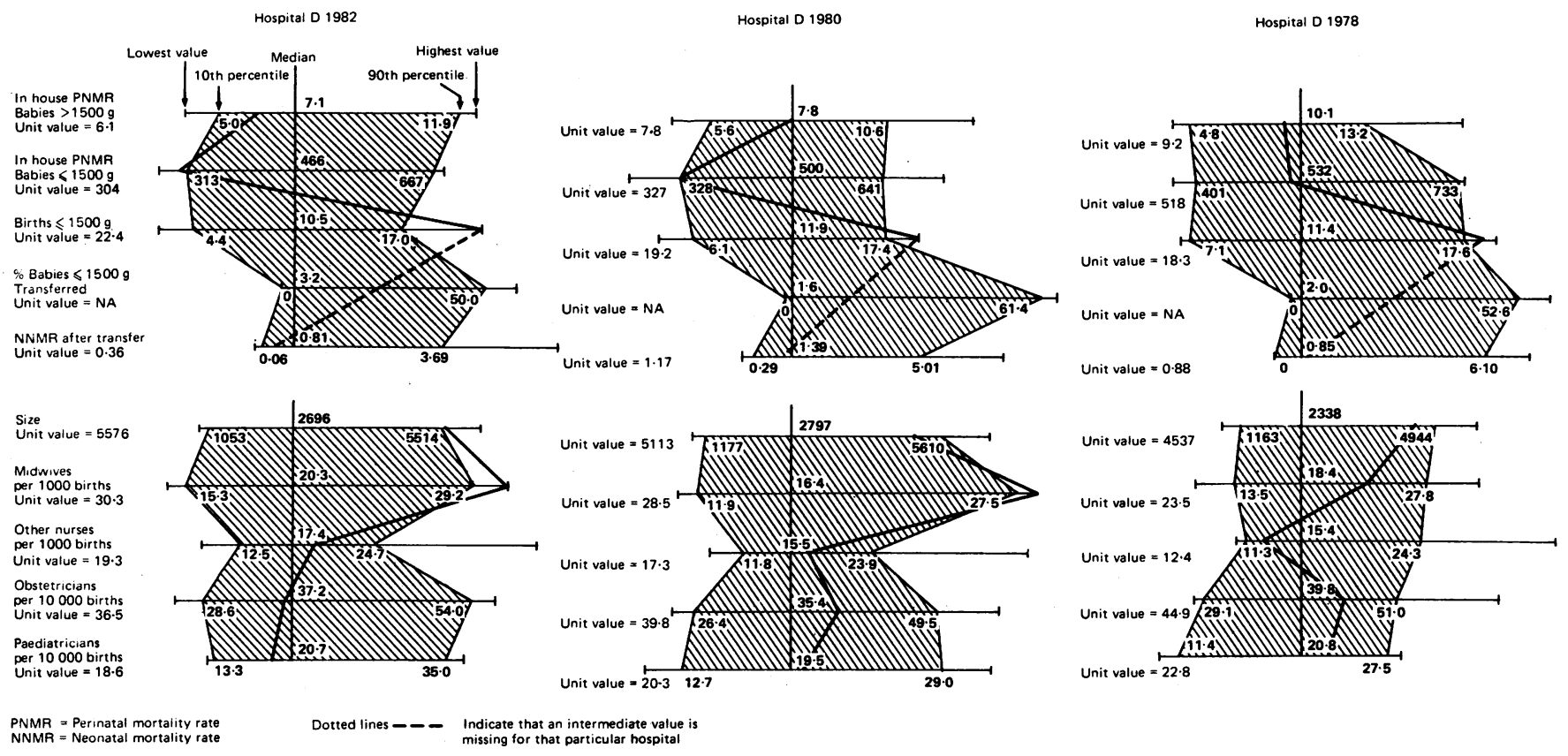

FIG 4-Management awareness profile (MAP) for hospital D in 1982, 1980, and 1978. See table II. NA=not available.

and regression coefficients cannot. Indeed, given the nature and quality of many of the data, such techniques might be inappropriate in any case. We are also aware that busy hospital staff have not got the time or training to analyse and interpret large amounts of raw data but would still welcome some indication of where their hospital stands in relation to other hospitals.

Obstetric or paediatric specialty committees, perinatal working parties, or local maternity services liaison committees all review services for maternity care in their region or district. Thus profiles that are drawn up to the committee's specification will help to find the units that are facing difficulties and will examine the justification for the special pleading that often takes place. The techniques used in MAPs have drawn on the pioneering work of both Selbmann ${ }^{13}$ and Yates. ${ }^{12}$ MAPs convey more information concisely than the simple percentile bars used by Yates. The extra dimensions conveyed by MAPs include, firstly, the way values for individual units are spread or concentrated between the highest and the lowest value (in effect showing the "shape of the hill" or distribution of values). Secondly, the absolute values for the units are shown as well as their rank rather than rank values alone as in simple percentile bars.

We have referred to the use of profiles similar to MAPs in the Bavarian Perinatal Survey. ${ }^{13}$ These profiles, which were adapted from a method previously used by psychologists, were hospital based, but they were principally concerned with clinical practice in the hospitals such as rates for caesarean sections, and not with variables such as staffing resources. In addition, the Bavarian
Although this paper has concentrated on an example from maternity care, the technique of using profiles for management information can be used throughout the health service where statistics are collected and where there is a demand for feedback. A large amount of data is collected yearly throughout the health service, but few staff below the level of the health authority have access to the data. At a time when the health services are being asked to develop an information strategy, ${ }^{15}$ the challenge to the emerging district and regional information services is to collaborate with client groups among health providers to design what they require. Because it is important that end users should have as much control as possible over the items included we are developing a flexible system for the production of MAPs using computerised colour graphics. As well as offering a range of items of information that would be limited onl'y by the scope and flexibility of a health authority's information system, a range of contours would be available to supplement the 90th and 10th percentile contours. An evaluation of whether such a service is well received, whether it improves the quality of routine statistics contributed from units, and whether it makes a difference to decision making still remains to be done.

We thank the staff at all the maternity units who helped us with our survey; the staff of West Midlands regional statistics and manpower sections; our colleagues who gave their time to comment on early drafts; and Lesley Mierh, who typed the paper. We were supported by research funds from the Department of Health and Social Security. 


\section{References}

1 Macfarlane AJ, Mugford M. Birth counts: statistics of pregnancy and childbirth. Vol I. London: HMSO, 1984 .

2 NHS/DHSS Steering Group on Health Services Information. First report to the Secretary of State. London: HMSO, 1982 .

3 McLachlan G, ed. Data, information and intelligence. London: Nuffield Provincial Hospitals Trust, 1985. (Occasional papers 4.)

4 Brotherton PG. How to make statistics count. Hospital and Health Services Review 1985;81:226-9. 5 Brown I, Elbourne D, Mutch L. Standard national perinatal data: a suggested minimum data set. Community Med 1981;3:298-306.

6 Mugford M, Mutch L, Elbourne D. Standard perinatal data: suggestions for regular review of facilities for perinatal care within a regional health authority. Community Med 1985;7:157-68.

7 Mutch L, Elbourne D. Standard national perinatal data: a suggested common core of tabulations. Community Med 1983;5:251-9.
8 Buzzell R, Gale B, Sultan R. Market share-a key to profitability. Harvard Business Review 1985;Jan-Feb:97-105.

9 National Health Service. Korner data model report. Birmingham: NHS Corporate Data Administration, 1985 .

10 Macfarlane AJ, Chalmers I. Problems in the interpretation of perinatal mortality statistics. In: Hull D, ed. Recent advances in paediatrics. London: Churchill Livingstone, 1981:1-12.

11 Department of Health and Social Security. Performance indicators for the NHS. An introduction. London: DHSS, 1985.

12 Yates JM, Davidge MG. Can you measure performance? Br Med f 1984;288:1935-6.

13 Selbmann $H$, Warnke $W$, Eissner $H$. Comparison of hospitals supporting quality assurance. Methods Inf Med 1982;21:75-80.

4 Sunderland R. Inaccurate coding corrupts medical information. Arch Dis Child 1985;6:593-4

15 Department of Health and Social Security. National framework for information management. London: DHSS, 1986. (Press release 86/105.)

(Accepted 12 December 1986)
Are vitamin supplements necessary for healthy full term babies during breast feeding?

If nature had intended breast fed babies to receive a vitamin supplement nature would have added the vitamin supplement to the breast milk. Any mother successfully breast feeding the full term baby knows that no supplements are necessary. The assumption is made, however, that the mother is in good health and that successful weaning takes place by the age of 6 months. Those babies receiving only breast milk towards their first birthday are at risk of deficiencies. Four vitamins/minerals are worthy of mention. There is no vitamin $\mathrm{K}$ in breast milk and it is therefore sensible to give vitamin $\mathrm{K}$, either by mouth or intramuscularly, at birth to breast fed babies. If the mother feels strongly about fluoride there will be insufficient in the breast milk. On theoretical grounds the vitamin D and iron content of breast milk does not satisfy the infant's basic needs. If $3.0 \mu \mathrm{g} / \mathrm{kg}$ of vitamin $D$ is necessary breast milk provides at best $0.4 \mu \mathrm{g} / \mathrm{kg}$. Clinic supplied vitamin drops (5) will provide $7 \mu \mathrm{g}$. Again the amount of iron in breast milk is only one tenth of that which is theoretically necessary. It is, however, better absorbed than the $0.1 \mathrm{mmol} / \mathrm{l}$ of elemental iron found in formula milks. As iron can theoretically impair the immunological function of lactoferrin in breast milk there can be no case for using it prophylactically. In summary, if the mother does not have osteomalacia, eats a good diet, and introduces solids from 4-6 months breast fed babies need no supplements.—J G BISSENDEN, consultant paediatrician, Birmingham.

Manufacturers recommend that the Copper-7 intrauterine contraceptive device should be changed after two years. I understand, however, that there is evidence that the device may be left in situ permanently if it is not causing problems. Is this so?

Since October 1986 the Copper-7 has been withdrawn from the British market. This has been done solely on financial grounds, primarily because the manufacturer cannot obtain medicolegal insurance cover for the device and without this cover the company will not make money out of it. The truth of the last statement is amply borne out by the fact that the company had to pay out $\$ 1.5 \mathrm{~m}$ in legal costs in a recent case in the United States which it won. The Copper-7 device, however, remains fully approved by the Committee on the Safety of Medicines. Both before and now since the withdrawal of Copper-7s from the market I see no reason to change the recommendation that it be used by any woman, after counselling, for a minimum of three years, since the identical device has always been licensed in North America for three years' use even though the data sheet over here states two years. Use beyond that time is also possible, as discussed below for copper devices generally, though the word "permanently" may be a bit too strong. To quote a recent book, ${ }^{1}$ without exception all studies have failed to show the expected upturn in pregnancy rate when follow up has extended to beyond four years for the Copper-7, the Copper-T, and the Multiload $250 .{ }^{2}$ In all long term studies, however, we are dealing with a less fertile population, by virtue of the fact that the most fertile women become pregnant within the early years and have their devices removed; hence the reported pregnancy rates in later years in the studies are based on the observation of a subgroup becoming (by selection) relatively infertile. This leaves the question that the individual woman seen after, say, three years of using her copper device might perhaps expect an almost zero subsequent pregnancy risk if she had the device replaced. On the other hand, reinsertion is uncomfortable and inconvenient at best and at worst potentially hazardous. Most women will accept continuation into the fourth or subsequent year of use of the devices mentioned, knowing that the pregnancy risk will be no greater than the risk they have already accepted during each of the first three years. Furthermore, I would have no hesitation in allowing a woman past the age of 45 to continue with the same intrauterine device until (as routinely recommended) one year after her menopause.

Two devices are available whose officially recommended intrauterine "life" is longer than the above. The Nova-T, bearing copper wire on a silver core, is recommended for five years and the new Ortho Gynae 380 Slimline with copper bands on the horizontal arms is recommended for four years. It is a tenable hypothesis that neither of these devices needs changing unless side effects develop or the woman desires pregnancy. I would emphasise, however, that there is as yet no proof of this statement; and in the present medicolegal climate any doctor who permits his patient to use her device for longer than the time recommended in the data sheet should counsel her along the lines of this answer and keep good contemporaneous records.-J GUILLEBAUD, senior lecturer in gynaecology, London.

1 Guillebaud J. Contraception-your questions answered. Edinburgh: Churchill-Livingstone, 1986 247-50.

2 Liskin L, Fox G. IUDs: an appropriate contraceptive for many women. Population Reports 1982; 10:B107.

A patient had a Starr-Edwards aortic prosthetic valve inserted in 1981 with pronounced improvement in his symptoms. Over the past few months the noise from his valve is preventing him from going to sleep. What advice should he be given?

The noise produced by the Starr-Edwards aortic valve is due to the silastic ball striking the cage during systole and diastole. It often rebounds and strikes yet again so that there is a series of high frequency clicks occurring in systole and diastole. These noises are usually much louder soon after surgery because they are conducted more readily to the nervous system by fluid in the pericardium and tissue oedema. They usually get softer with time, however, and since this prosthesis was inserted six years ago, I would expect that the level of noise is at its lowest. Patients who have a Starr-Edwards prosthesis usually get accustomed to the noise, which has often been likened to the railway train at the bottom of the garden. When you first move into the house you notice the noise but after a while you do not notice it at all. If the noise of the valve has become worrying then I fear there is nothing that can be done about it other than apply the soothing lotion of time. It is unlikely that any surgeon would want to remove a successful Starr-Edwards aortic prosthesis and replace it with a xenograft which would be much quieter, but if the subject is being distracted by the noise beyond the bounds of reason, then this may be recommended.-E B RAFTERY, consultant cardiologist, London.

A man in his 30s had a pneumothorax treated by a thoracotomy and pleurodesis since when he has been fit. Should he be allowed to fly in commercial aircraft?

The concern is of a pneumothorax occurring during flight. With the lowered ambient pressure the pneumothorax might increase in size and cause cardiopulmonary embarrassment. The risk of a pneumothorax recurring is about $35 \%$ after the first episode, $50 \%$ after the second, and $80 \%$ after the third. ${ }^{1}$ Most recur within six months. The actual risk of a recurrence in the short period of a flight is small. In-flight pneumothorax is uncommon. ${ }^{12}$ After definitive treatment, either pleurodesis or preferably pleurectomy, the risk of recurrence is so small that unlimited flying as a passenger may be allowed.-J A C HOPKIRK, consultant respiratory physician, Midhurst.

1 Cran IR, Rumball CA. Survey of spontaneous pneumothoraces in the Royal Air Force. Thorax 1967;22:462-5.

2 Flux M, Dille JR. In-flight spontaneous pneumothorax. A case report. Aerospace Medicine 1969;40:660-2.

3 Hopkirk JAC, Pullen MJ, Fraser JR. Pleurodesis: the results of treatment for spontaneous pneumothorax in the Royal Air Force. Aviat Space Environ Med 1983;54:158-60. 